\title{
500TH MEETING OF THE CAMBRIDGE ENTOMOLOGICAL CLUB
}

In celebration of the 500th regular meeting of the Cambridge Entomological Club a combined dinner and meeting was held on Tuesday, December 15th, at the Faculty Club of Harvard University. Following an excellent dinner, in which thirty persons participated, the toastmaster of the evening, W. L. W. Field, opened the proceedings by reading from the minutes of the first meeting in 1874. Professor Nathan Banks was the first of the after-dinner speakers, and spoke of the need of specialization and the furtherance of systematic entomology. Vice-President C. W. Collins, who was in charge of the meeting, brought the felicitations of the Bureau of Entomology, and traced the development of economic entomology during the existence of the club. Professor C. T. Brues gave a delightfully humorous talk on some of the peculiar and amusing incidents encountered in connection with his office as editor of "Psyche." Mr. C. W. Johnson sketched the course of the club since its inception in 1874 as an offspring of the Boston Society of Natural History to the present; he also bore the congratulations of the parent organization and its thanks for the cooperation of the members of the Cambridge Entomological Club in contributing materially to the establishment of the extensive and representative collection of New England insects in the Boston Museum of Natural History. Professor A. P. Morse reminisced on the earlier days of the club, giving intimate glimpses of meetings at the home of Samuel Scudder.

Following the after-dinner speeches, an interesting motion picture film illustrating the life history of the yellowfever mosquito was shown. 
The scientific paper of the evening was given by Dr. Joseph Bequaert on "Some Problems of Medical Entomology in Guatemala."

During the course of the evening, a rising vote was passed authorizing a message in recognition of the death of A. G. Weeks, during the preceding week. Messages of respect, remembrance, and affection were also drawn up in honor of Mr. Samuel Henshaw and Professor Roland Thaxter.

It was not until 11:00 P. M. that this, one of the most enthusiastic and highly successful meetings of the Cambridge Entomological Club, was brought to adjournment. 

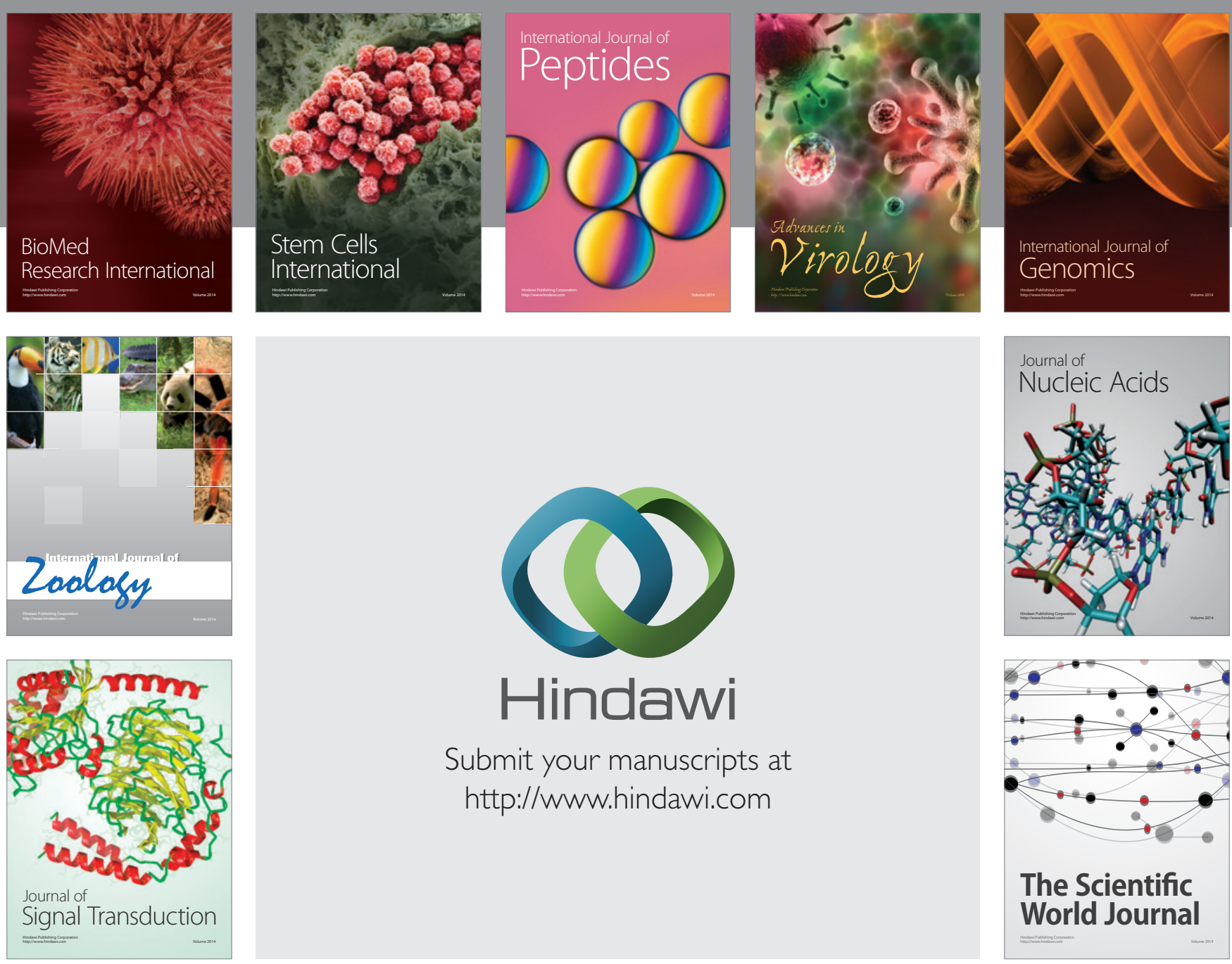

Submit your manuscripts at

http://www.hindawi.com
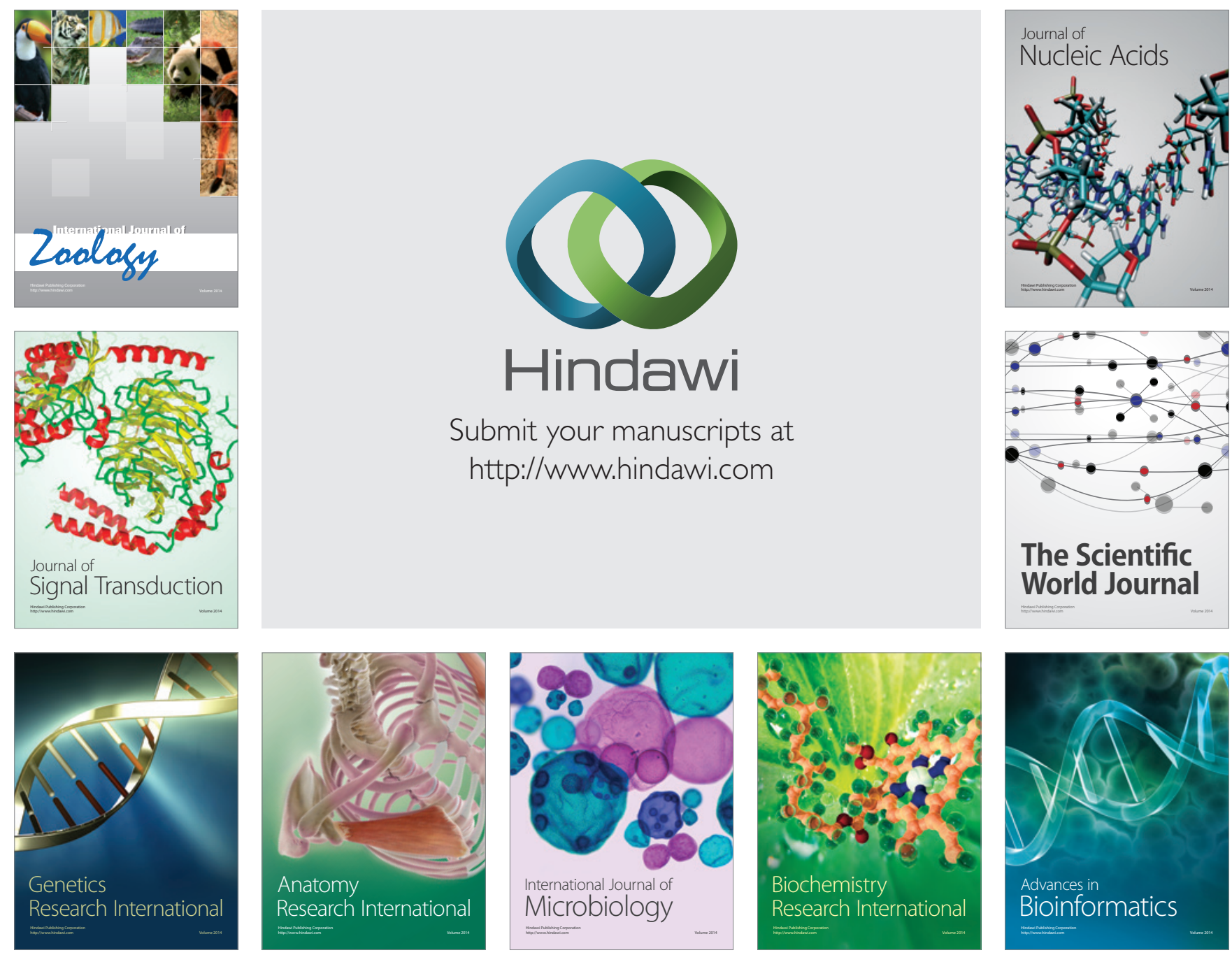

The Scientific World Journal
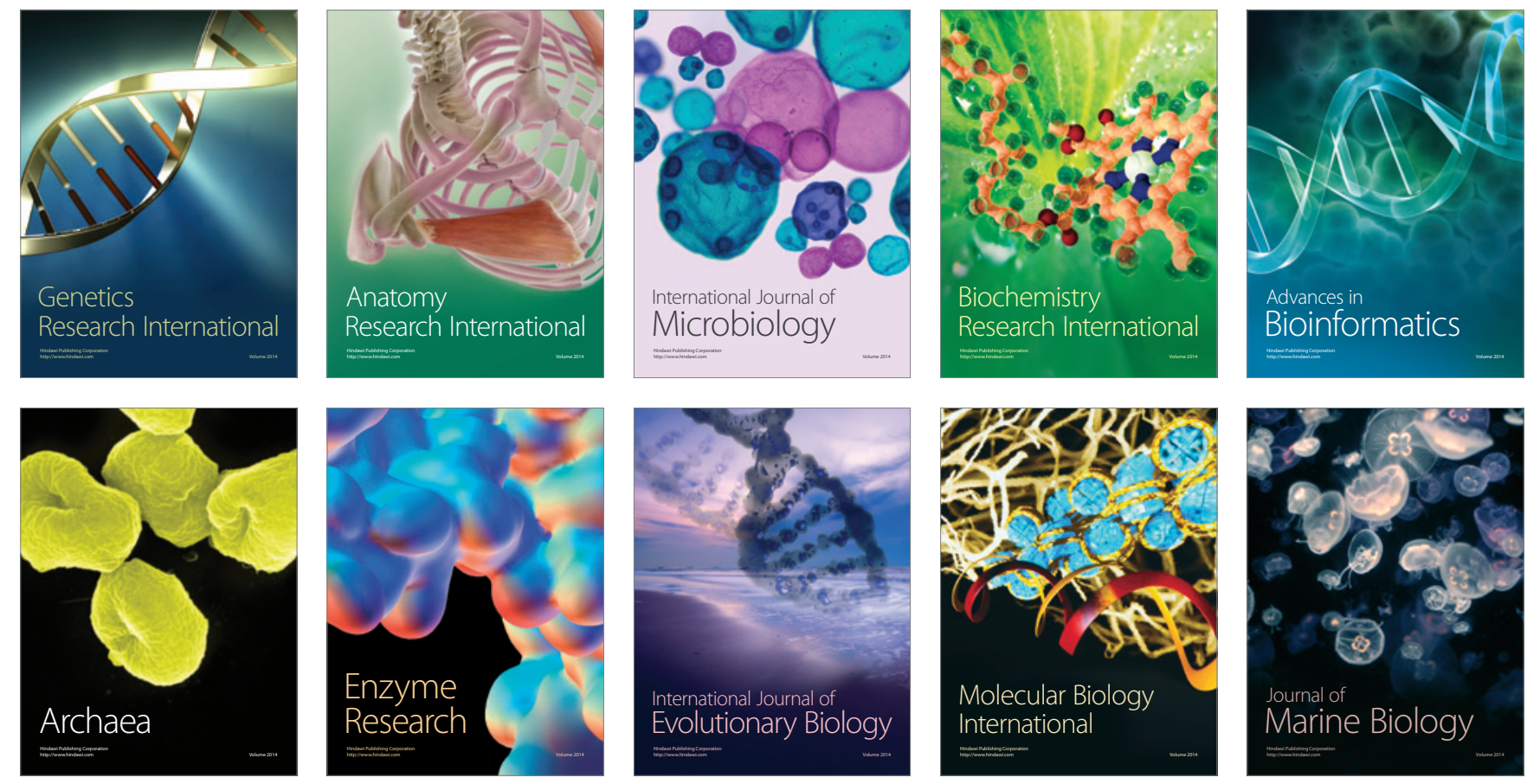